\title{
EFICIÊNCIA DE SOLVENTES NA OBTENÇÃO E CARACTERIZAÇÃO DE CORANTES DE URUCUM (Bixa orellana L.)
}

\author{
POLLYANNA IBRAHIM SILVA* \\ ALINE MANKE NACHTIGALL** \\ PAULO CESAR STRINGHETA***
}

\begin{abstract}
O objetivo deste trabalho foi verificar a eficiência de diferentes solventes na extração de pigmentos das sementes de urucum, bem como produzir e analisar as características dos corantes obtidos. Os solventes empregados foram $\mathrm{KOH} 0,6 \%, \mathrm{NH}_{4} \mathrm{OH}$ $2 \%, \mathrm{NH}_{4} \mathrm{OH}$ etanólico $2 \%$ e etanol comercial. A partir dos extratos obtidos com $\mathrm{KOH} 0,6 \%$ e $\mathrm{NH}_{4} \mathrm{OH} 2 \%$ produziram-se corantes em pó em spray-dryer, e os extratos hidroalcoólicos e alcoólicos deram origem a corantes em pasta. A eficiência da extração foi avaliada pelo residual de bixina presente nas sementes ao término das extrações e os corantes foram caracterizados com relação ao teor de umidade, sólidos totais, cinzas, resíduo de amônia, teor de potássio e pelo teor de bixina e norbixina. $\mathrm{O}$ solvente mais eficiente foi o $\mathrm{NH}_{4} \mathrm{OH}$ etanólico $2 \%$. Encontrou-se o maior teor de bixina no corante em pasta produzido com etanol $\left(27,7{\left.\mathrm{~g} .100 \mathrm{~g}^{-1}\right) \mathrm{e} \mathrm{a}}^{-1}\right.$ despeito do que tem sido relatado na literatura, as concentrações de álcali empregadas não foram suficientes para converter a bixina em norbixina e seu sal. Os diferentes solventes influenciaram o aumento da concentração de compostos presentes nos corantes produzidos, como cinzas, compostos nitrogenados e potássio. Em todos os corantes elaborados o pigmento majoritário foi a bixina, mesmo em extratos obtidos por extração com solução alcalina.
\end{abstract}

PALAVRAS-CHAVE: BIXINA; SAL DE NORBIXINA; MÉTODOS DE EXTRAÇÃO.

* Doutoranda em Ciência e Tecnologia de Alimentos, Universidade Federal de Viçosa (UFV), Viçosa, MG (e-mail: pollyannaibrahim@yahoo.com.br).

** Pós-doutora em Ciência e Tecnologia de Alimentos, UFV, Viçosa, MG (e-mail: anachtigall@gmail.com).

*** Doutor em Ciência de Alimentos, UFV, Viçosa, MG (e-mail: pstringheta@yahoo.com.br). 


\section{INTRODUÇÃO}

Do pericarpo seco das sementes de urucum (Bixa orellana L.) obtém-se corante natural muito usado em vários setores industriais. O baixo custo de produção e sua baixa toxicidade tornam esse pigmento muito atrativo e conveniente em substituição a muitos corantes sintéticos (AGNER et al., 2004). O corante de urucum apresenta coloração amarelo-alaranjada, constituída majoritariamente pelo diapocarotenóide lipossolúvel amarelo 9'-cis-bixina (cerca de 80\%). A bixina ocorre naturalmente na forma cis, porém durante o processo de extração pode ser isomerizada à forma trans (COSTA e CHAVES, 2005).

Os métodos de extração utilizados para a produção de corantes de urucum a partir da semente podem produzir bixina ou, por meio da hidrólise aquosa, a extração simultânea da norbixina. Talvez o fato que torna o urucum uma das matérias-primas mais interessantes para a extração de corantes seja a possibilidade de se obter do mesmo tipo de semente, corantes solúveis em água e corantes solúveis em óleo, alterando-se apenas o solvente de extração (LIMA et al., 2001). Os métodos mais utilizados para extrair o pigmento das sementes são a extração alcalina (sal da norbixina), a extração em óleo (bixina) e a extração com solvente, obtendo-se produto com maior grau de pureza. Tais corantes diferem entre si quanto à solubilidade e pigmentação (PRENTICE-HERNANDEZ e RUSIG, 1992).

No curso da extração e do processamento dos pigmentos de urucum, vários produtos de rearranjo ou de degradação podem ser formados. Por exemplo, aquecimento moderado pode causar a conversão da cis-bixina para seus isômeros trans (PRENTICE-HERNANDEZ, RUSIG e CARVALHO, 1992). O aquecimento mais drástico pode causar degradação da bixina, originando grande número de produtos, principalmente compostos de degradação com cadeia carbônica contendo 17 carbonos, conhecidos como $C_{17}$. A hidrólise alcalina feita sob condições controladas produz o ácido dicarboxílico livre norbixina, que assim como a bixina pode existir em ambas as formas, cis e trans. Assim, da bixina são obtidos os demais pigmentos do urucum, como a norbixina (lipossolúvel), o sal da norbixina (hidrossolúvel) e os produtos de degradação térmica, que têm como características a lipossolubilidade e a coloração amarela mais estável. Deve-se ressaltar que o corante hidrossolúvel do urucum é o sal da norbixina, que pode ser convertido em norbixina pela precipitação ácida e, nessa forma, o pigmento deixa de ser solúvel em água (PIMENTEL e STRINGHETA, 1999).

O objetivo deste trabalho foi avaliar a eficiência de distintos sistemas solventes na extração de pigmentos da semente de urucum, produzir corantes por diferentes metodologias e analisar as características dos corantes obtidos em cada processo.

\section{MATERIAL E MÉTODOS}

\subsection{EXTRAÇÃO DOS PIGMENTOS}

$\mathrm{Na}$ extração dos pigmentos das sementes de urucum, da variedade Embrapa 36/37, foram empregados os seguintes solventes: $\mathrm{KOH} 0,6 \% ; \mathrm{NH}_{4} \mathrm{OH} 2 \%$; $\mathrm{NH}_{4} \mathrm{OH}$ etanólico $2 \%$ (solução hidroalcoólica com 60\% de etanol) e etanol comercial (92,8\%) (PIMENTEL, 1995; SILVA 2007).

Alíquotas de $100 \mathrm{~g}$ de sementes foram misturadas aos solventes extratores citados anteriormente na proporção de 1:6 (p/v). Após a adição do solvente, as amostras foram submetidas à extração sob agitação constante a 108 rpm, com auxílio de banho-maria com agitação e controle de temperatura da marca Nova Ética, modelo 304/D (São Paulo, Brasil). As extrações foram realizadas ao abrigo da luz, a $25^{\circ} \mathrm{C}$, por $1 \mathrm{~h}$. Ao término da extração, os extratos foram filtrados (SILVA, 2007). 


\subsection{PRODUÇÃO DOS CORANTES}

A partir dos extratos obtidos no item 2.1 produziram-se corantes em pó e em pasta. $\mathrm{Na}$ produção dos corantes em pó corrigiu-se o pH dos extratos obtidos pela extração com solventes

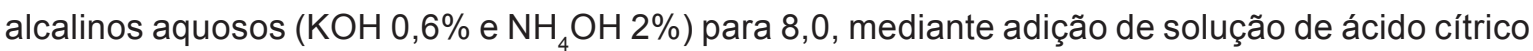
saturado. Em seguida, ajustou-se o teor de sólidos totais em 16,5\% com acréscimo de maltodextrina e submeteram-se os extratos a aquecimento a $40^{\circ} \mathrm{C}$. Os extratos assim obtidos foram secos em mini spray-dryer da marca Buchi, modelo B - 191 (Buchi, Switzerland), nas seguintes condições operacionais: vácuo (30 mbar), temperatura do ar de entrada $\left(180 \pm 5^{\circ} \mathrm{C}\right.$ ), temperatura do ar de saída $\left(80 \pm 5^{\circ} \mathrm{C}\right)$ e pressão manométrica positiva, conforme metodologia adaptada de PIMENTEL (1995). Após a secagem, os corantes na forma de pó foram acondicionados em frascos de vidro âmbar e armazenados em freezer $\left(-18 \pm 2^{\circ} \mathrm{C}\right)$.

Para a produção do corante de urucum em pasta utilizaram-se os extratos hidroalcóolicos e alcoólicos, os quais não poderiam ser secos em spray-dryer. O extrato hidroalcoólico de $\mathrm{NH}_{4} \mathrm{OH}$ $2 \%$ foi acidificado com solução de ácido cítrico saturado a $\mathrm{pH} 3,5$, visando a precipitação do pigmento. $O$ extrato acidificado foi mantido em repouso por 12 horas para a decantação da norbixina. Já para o extrato alcoólico aguardou-se a precipitação durante 4 horas, conforme descrito por PRENTICE-HERNANDEZ e RUSIG (1992). Após a separação, o sobrenadante foi eliminado e a fase inferior contendo o pigmento recuperada. As "massas" corantes obtidas foram recuperadas e submetidas à secagem em estufa com circulação forçada de ar a $45^{\circ} \mathrm{C}$, durante 30 minutos. $\mathrm{O}$ corante em pasta obtido foi acondicionado em saco de polietileno de alta densidade, e armazenado em freezer $\left(-18 \pm 2^{\circ} \mathrm{C}\right)$.

\subsection{DETERMINAÇÃO DA EFICIÊNCIA DA EXTRAÇÃO}

Para determinar a eficiência dos diferentes solventes na extração dos pigmentos das sementes de urucum, o teor de bixina foi avaliado antes e após a extração, utilizando-se espectrofotometria no comprimento de onda de máxima absorção $\left(470 \mathrm{~nm}\right.$ ) e empregando $\mathrm{E}_{1 \mathrm{~cm}}{ }^{1 \%}=2.826$ (STRINGHETA et al. 1999; TOCCHINI e MERCADANTE, 2001), com auxílio do espectrofotômetro Shimadzu modelo UV 1601PC (Kyoto, Japan).

\subsection{CARACTERIZAÇÃO DOS CORANTES PRODUZIDOS}

Os corantes em pó e em pasta foram caracterizados quanto ao seu teor de umidade, sólidos totais, cinzas, residual de amônia e de potássio, e conteúdos de bixina e norbixina.

As determinações de umidade, sólidos totais, cinzas e residual de amônia foram conduzidas de acordo com os métodos analíticos do INSTITUTO ADOLFO LUTZ (1985). O teor de potássio foi analisado a partir das cinzas obtidas do material por meio de espectroscopia de absorção atômica (MILLER, 1999).

Os teores de bixina e norbixina nos corantes em pó e em pasta foram determinados por espectrofotometria (bixinóides totais) e por cromatografia a líquido de alta eficiência (CLAE).

$\mathrm{Na}$ avaliação por espectrofotometria, o teor de pigmentos no corante em pasta produzido pela extração com etanol comercial foi determinado mediante sua diluição em clorofórmio, utilizandose o comprimento de onda de máxima absorção de $470 \mathrm{~nm}$ e $\mathrm{E}_{1 \mathrm{~cm}}{ }^{1 \%}=2.826$ (TOCCHINI e MERCADANTE, 2001). Já o teor de pigmentos nos corantes produzidos pela extração com $\mathrm{KOH}$ $0,6 \%, \mathrm{NH}_{4} \mathrm{OH} 2 \%$ e NH $\mathrm{NH}_{4} \mathrm{OH}$ etanólico $2 \%$ baseou-se na diluição da amostra em solução de $\mathrm{KOH}$ e leitura no comprimento de onda de $482 \mathrm{~nm}$, empregando $\mathrm{E}_{1 \mathrm{~cm}}{ }^{1 \%}=2.870$ (LEVY e RIVADENEIRA, 2000). Para as análises espectrofotométricas utilizou-se espectrofotômetro Shimadzu modelo UV 1601PC (Kyoto, Japan). 
Para a caracterização e quantificação dos pigmentos de urucum por CLAE empregou-se fase móvel de acetonitrila:ácido acético 5\% (75:25), conforme BARETH, STROHMAR e KITZELMANN (2002). Utilizou-se cromatógrafo a líquido da marca Shimadzu, modelo LC-10 AD VP, detector UV-Visível e integrador-processador Shimadzu SCL-10A VP, com duas bombas e sistema manual de injeção. Pesaram-se (exatamente) $10 \mathrm{mg}$ dos corantes e as amostras, após diluídas convenientemente, foram filtradas em membrana Milipore ${ }^{\circledR}$ de nylon, com diâmetro de poro de $0,2 \mu \mathrm{m}$ e injetadas no sistema CLAE. Utilizou-se coluna de fase reversa Lichrospher $100 \mathrm{RP}-18(25 \mathrm{~cm} \times 4,0 \mathrm{~mm} ; 5 \mu \mathrm{m})$ marca Merck (Darmstadt, Germany), protegida por pré-coluna CLC G-ODS, da marca Shimadzu (Kyoto, Japan). A vazão da fase móvel foi de 1,0 mL. $\mathrm{min}^{-1}$, sendo os espectros adquiridos no comprimento de onda de $460 \mathrm{~nm}$. O volume de amostra injetado foi de $50 \mu \mathrm{L}$.

A quantificação ocorreu pelo método do padrão externo. Os padrões de bixina $(97,8 \%)$ e norbixina $(91,3 \%)$ foram preparados no laboratório, a partir de sementes de urucum (por não estarem disponíveis comercialmente). As curvas analíticas (área versus concentração) para bixina e norbixina foram obtidas através da análise de soluções dos padrões com concentrações de 50 a $500 \mathrm{mg} \cdot \mathrm{L}^{-1}$, obtendo-se coeficientes de correlação $\left(R^{2}\right)$ de 0,986 e 0,981, respectivamente.

\subsection{DELINEAMENTO EXPERIMENTAL}

Empregou-se delineamento do tipo inteiramente casualizado com três repetições. Os dados foram avaliados por análise de variância e comparação de médias pelo teste de Tukey $(p<0,05)$, com auxílio do software SAS ${ }^{\circledR}$, versão 9.1 (SAS Institute Inc., 2002).

\section{RESULTADOS E DISCUSSÃO}

\subsection{EFICIÊNCIA DA EXTRAÇÃO}

A Tabela 1 apresenta os teores médios de bixina das sementes esgotadas, obtidos após a extração com os solventes $\mathrm{KOH} 0,6 \%, \mathrm{NH}_{4} \mathrm{OH} 2 \%, \mathrm{NH}_{4} \mathrm{OH}$ etanólico $2 \%$ e etanol comercial.

\section{TABELA 1 - TEORES MÉDIOS DE BIXINA NAS SEMENTES ESGOTADAS APÓS EXTRAÇÃO COM OS DIFERENTES SOLVENTES EXTRATORES E EFICIÊNCIA DOS SOLVENTES}

Solvente extrator

Teor de bixina* $\left(\mathrm{g} .100 \mathrm{~g}^{-1}\right)$
Eficiência (\%)

\begin{tabular}{lll}
\hline $\mathrm{KOH} \mathrm{0,6 \%}$ & $0,35 \pm 0,01 \mathrm{~b}$ & $77,14 \mathrm{~b}$ \\
$\mathrm{NH}_{4} \mathrm{OH} \%$ & $0,34 \pm 0,03 \mathrm{~b}$ & $79,41 \mathrm{~b}$ \\
$\mathrm{NH}_{4} \mathrm{OH}$ etan 2\% & $0,23 \pm 0,02 \mathrm{c}$ & $84,00 \mathrm{a}$ \\
Etanol & $1,05 \pm 0,03 \mathrm{a}$ & $60,00 \mathrm{c}$
\end{tabular}

Médias seguidas pela mesma letra não diferem entre si pelo teste de Tukey a $5 \%$ de probabilidade.

*Média \pm desvio-padrão. 
A melhor extração ocorreu com a solução hidroalcoólica de $\mathrm{NH}_{4} \mathrm{OH} 2 \%$, uma vez que nessas condições obteve-se o menor teor de pigmentos residuais nas sementes e, consequentemente, a maior eficiência na extração. Os solventes aquosos $\mathrm{KOH} 0,6 \%$ e $\mathrm{NH}_{4} \mathrm{OH} 2 \%$ não diferiram significativamente pelo teste de Tukey a $5 \%$ de probabilidade, indicando eficiência semelhante. Já o etanol comercial apresentou teor de bixina residual mais elevado, sendo o solvente menos eficiente na extração da bixina nas condições deste estudo.

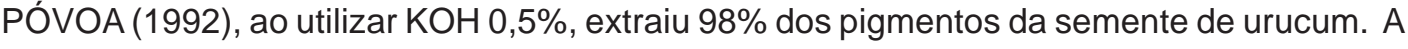
maior retenção de pigmentos na semente ocorreu quando utilizou água como solvente, correspondendo

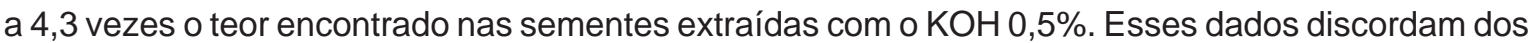
constatados no presente estudo, pois obteve-se extração de aproximadamente $77 \%$ dos pigmentos presentes nas sementes usando $\mathrm{KOH} 0,6 \%$.

\subsection{CARACTERIZAÇÃO DOS CORANTES PRODUZIDOS}

A Tabela 2 apresenta os teores médios de umidade, sólidos totais, cinzas, residual de amônia e potássio para os corantes em pó e em pasta.

\section{TABELA 2 - CARACTERIZAÇÃO DOS CORANTES EM PÓ E EM PASTA DE URUCUM OBTIDOS COM OS DIVERSOS SOLVENTES}

\section{Corantes Concentrados}

Determinações (\%) $\quad$ Em pó $\quad$ Em pasta

\begin{tabular}{lcccc}
\cline { 2 - 5 } & KOH 0,6\% & $\mathbf{N H}_{4} \mathrm{OH} \mathrm{2 \%}$ & $\mathbf{N H}_{4} \mathrm{OH}$ et. 2\% & Etanol \\
\hline Umidade & $4,70 \pm 0,33 \mathrm{~b}$ & $8,75 \pm 0,41 \mathrm{~b}$ & $25,62 \pm 0,84 \mathrm{a}$ & $17,47 \pm 0,90 \mathrm{a}$ \\
Sólidos totais & $95,29 \pm 0,33 \mathrm{a}$ & $91,25 \pm 0,41 \mathrm{a}$ & $74,38 \pm 0,84 \mathrm{~b}$ & $82,53 \pm 0,90 \mathrm{~b}$ \\
Cinzas & $2,98 \pm 0,43 \mathrm{a}$ & $0,55 \pm 0,01 \mathrm{c}$ & $0,26 \pm 0,02 \mathrm{c}$ & $2,07 \pm 0,11 \mathrm{~b}$ \\
Residual de amônia $^{*}$ & - & $1,72 \pm 0,02 \mathrm{a}$ & $1,69 \pm 0,14 \mathrm{a}$ & $0,56 \pm 0,04 \mathrm{~b}$ \\
Teor de potássio $^{*}$ & $1,00 \pm 0,08^{\mathrm{a}}$ & - & - & $0,47 \pm 0,07 \mathrm{~b}$
\end{tabular}

Médias seguidas pela mesma letra em cada linha não diferem entre si pelo teste de Tukey a 5\% de probabilidade.

* dados expressos em base seca.

Ao avaliar os resultados apresentados na Tabela 2 percebe-se, quanto ao teor de umidade e sólidos totais, que os corantes podem ser divididos em dois grupos como consequência do processo de secagem. Os corantes em pó obtidos por secagem em spray-dryer apresentaram o menor teor de umidade e por conseguinte maior teor de sólidos totais, já os corantes em pasta secos em estufa caracterizaram-se pelo conteúdo de umidade mais elevado e menor teor de sólidos totais.

O corante que apresentou o maior teor de cinzas foi produzido pela extração com $\mathrm{KOH}$ $0,6 \%$, provavelmente devido à formação do sal citrato de potássio na etapa de neutralização do $\mathrm{pH}$ com o ácido cítrico. O corante em pasta produzido pela extração com o etanol comercial apresentou o segundo maior teor de cinzas, o qual pode estar relacionado à presença de impurezas minerais 
no solvente. Já o reduzido teor de cinzas encontrado nos corantes produzidos com os extratos de $\mathrm{NH}_{4} \mathrm{OH} 2 \%$ pode ser justificado pela volatilização de sais de amônio. Segundo GOMES, SILVA e SILVA (2003), alguns sais podem sofrer redução ou volatilização durante o aquecimento em mufla. Dados discrepantes foram encontrados por PÓVOA (1992) ao empregar o solvente etanol 95\%, água, óleo de soja e $\mathrm{KOH} 0,5 \%$ na extração dos pigmentos de urucum. Foi constatado teor de cinzas de $35,59 \%$ para o corante produzido com $\mathrm{KOH} 0,5 \%$ e de $1,57 \%$ para o corante produzido com etanol. O nível elevado de cinzas no extrato alcalino poderia corresponder, em grande parte, ao soluto da solução extratora.

Analisando-se o teor residual de amônia e o teor de potássio (Tabela 2) fica claro o incremento do primeiro nos corantes produzidos com $\mathrm{NH}_{4} \mathrm{OH}$ e do segundo no corante produzido com o extrato oriundo do solvente $\mathrm{KOH}$. Esse comportamento justifica-se pela formação dos sais de norbixinato de amônio e potássio, assim como citrato de amônio e potássio, já que na extração com soluções alcalinas pode ocorrer a saponificação da bixina originando o sal de norbixina, e/ou pela formação do sal citrato no momento da neutralização do pH dos extratos. No entanto, a presença de nitrogênio e potássio no corante produzido com etanol pode ser consequência de material proteico e compostos contendo o mineral potássio arrastados das sementes durante a extração, ou ser proveniente de impurezas do solvente.

$\mathrm{Na}$ Tabela 3 podem ser visualizados os teores de bixina e norbixina presentes nos corantes, determinados por CLAE e por espectrofotometria.

\section{TABELA 3 - TEORES DE BIXINA E NORBIXINA DOS CORANTES EM PÓ E EM PASTA OBTIDOS POR CLAE E POR ESPECTROFOTOMETRIA}

\begin{tabular}{|c|c|c|c|c|}
\hline \multirow{3}{*}{$\begin{array}{l}\text { Teor de Pigmento } \\
\left(\mathbf{g} .100 \mathrm{~g}^{-1}\right)\end{array}$} & \multicolumn{4}{|c|}{ Corantes Concentrados } \\
\hline & \multicolumn{2}{|c|}{ Em pó } & \multicolumn{2}{|c|}{ Em pasta } \\
\hline & $\mathrm{KOH} \mathrm{0,6 \%}$ & $\mathrm{NH}_{4} \mathrm{OH} 2 \%$ & $\mathrm{NH}_{4} \mathrm{OH}$ etan2\% & Etanol \\
\hline Bixina - CLAE & $1,11 \pm 0,09$ & $0,99 \pm 0,15$ & $19,4 \pm 0,90$ & $27,7 \pm 1,00$ \\
\hline Norbixina - CLAE & $0,16 \pm 0,01$ & $0,43 \pm 0,07$ & $0,91 \pm 0,25$ & $1,08 \pm 0,33$ \\
\hline Bixinóides totais - CLAE & $1,27 \pm 0,10$ & $1,42 \pm 0,16$ & $20,3 \pm 1,17$ & $28,8 \pm 1,40$ \\
\hline Bixinóides totais - espectro & $1,19 \pm 0,05$ & $1,59 \pm 0,06$ & $20,5 \pm 0,80$ & $33,5 \pm 0,07$ \\
\hline \% Variação ${ }^{1}$ & 6,72 & 10,7 & 0,97 & 14,0 \\
\hline
\end{tabular}

${ }^{1}$ Variação entre o percentual de pigmentos obtido por cromatografia em relação à análise espectrofotométrica.

Como os corantes em pó e em pasta foram concentrados por métodos distintos (spray-dryer e em estufa), seus teores de pigmentos não foram comparados estatisticamente.

No processo de produção de corantes por spray-dryer, apesar de se produzirem corantes com baixos teores de umidade, as concentrações de pigmento nos pós não foram as mais elevadas em relação aos processos de secagem em estufa. Esse fato está relacionado à adição de maltodextrina na proporção de uma parte de extrato para 10 partes de maltodextrina. Assim, a maltodextrina contribuiu para o peso das amostras, mas não para o seu poder corante.

O corante produzido pela extração em etanol e posterior secagem em estufa foi o que apresentou o maior teor e proporção de bixina (27,7 g.100 $\mathrm{g}^{-1} ; 93 \%$ dos pigmentos). Resultado muito inferior ao reportado por SOUZA (2000) ao produzir extratos concentrados de urucum (70 a 
72\%) extraídos com etanol. Tal discrepância pode ser justificada pela diferença de umidade final dos produtos avaliados.

PIMENTEL e STRINGHETA (1999) produziram corantes de urucum em pó por meio de precipitação ácida e secagem em estufa, a partir da solução extratora de $\mathrm{NH}_{4} \mathrm{OH} 0,52 \mathrm{~N}$ em etanol a $58 \%$. Encontraram teor médio de norbixina nos corantes em pó de $22,57 \%$, semelhante ao conteúdo de pigmento do corante produzido com solução aquosa de $\mathrm{NH}_{4} \mathrm{OH} 2 \%$ no presente trabalho (Tabela 3).

Pela Tabela 3 percebe-se que a bixina foi o carotenóide majoritário presente em todos os corantes produzidos, o que também pode ser verificado nos cromatogramas apresentados na Figura 1.
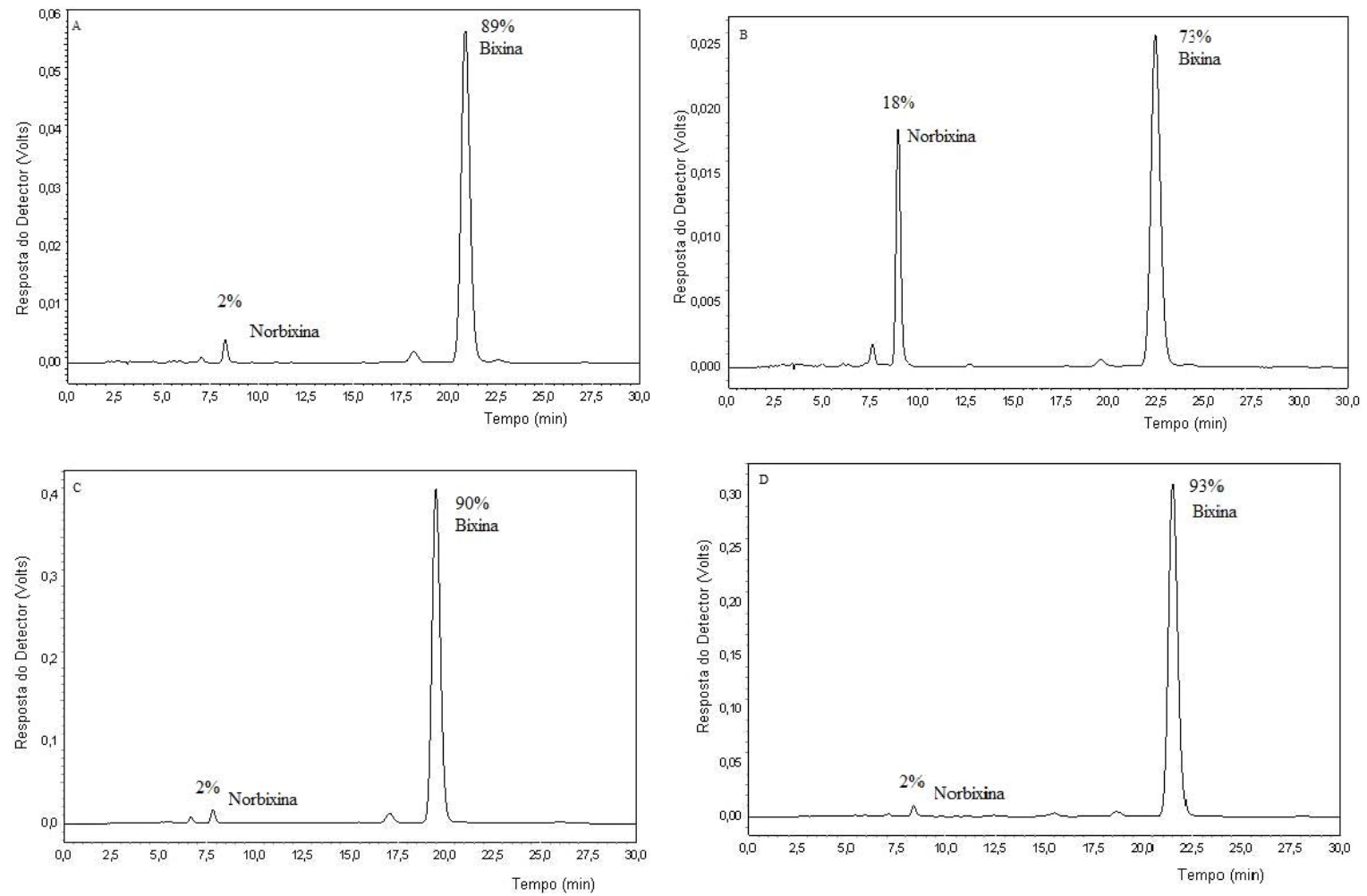

\section{FIGURA 1 - CROMATOGRAMAS OBTIDOS POR CLAE DOS CORANTES EM PÓ E EM PASTA PRODUZIDOS POR EXTRAÇÃO COM KOH 0,6\% (A), $\mathrm{NH}_{4} \mathrm{OH} 2 \%$ (B), $\mathrm{NH}_{4} \mathrm{OH}$ ETANÓLICO 2\% (C) E ETANOL COMERCIAL (D)}

Condições cromatográficas: coluna Lichrospher 100 rp-18 e acetonitrila:ácido acético 5\% (75:25) como fase móvel com fluxo de $1 \mathrm{ml} \cdot \mathrm{min}^{-1}$. Detecção a $460 \mathrm{~nm}$.

PRENTICE-HERNANDEZ, RUSIG e CARVALHO (1992) estudaram o efeito do pH na extração de pigmentos de urucum em extratos alcalinos e verificaram que o $\mathrm{pH}$ ideal para a extração de bixina é 10,74. Segundo tais autores, em valores de pH superiores a 11,00 ocorre a saponificação do grupo éster da bixina, formando a norbixina de forma irreversível. Esses resultados diferem dos obtidos no presente trabalho, na medida em que maior $\mathrm{pH}$ de extração não possibilitou a formação da norbixina quando comparado ao menor pH de extração em que houve a saponificação parcial ( $\mathrm{KOH} 0,6 \%$ - pH 12,$4 ; \mathrm{NH}_{4} \mathrm{OH} 2 \%$ - pH 10,5). Esse comportamento evidencia a influência do tipo de álcali na reação de saponificação. 
Observou-se que tanto a bixina quanto a norbixina (Tabela 3) foram extraídas com o $\mathrm{NH}_{4} \mathrm{OH}$ $2 \%$, ocorrendo saponificação parcial do grupo éster da bixina em sua forma hidrossolúvel, o sal da norbixina. A saponificação parcial obtida reforça a hipótese da dependência da reação de saponificação em relação à natureza do álcali, à sua concentração e ao tempo de extração.

A bixina foi o carotenóide majoritário encontrado no corante em pasta extraído com etanol comercial (93\%), justificado pelo fato da extração ter ocorrido em $\mathrm{pH}$ próximo à neutralidade. Nesse $\mathrm{pH}$, a saponificação do grupamento éster da bixina para formar a norbixina não ocorre ou ocorre em quantidade insignificante.

De acordo com a Tabela 3, as metodologias de quantificação de pigmentos por CLAE e por espectrofotometria retornaram resultados parecidos. No entanto, a CLAE constitui método mais preciso devido à quantificação de pigmentos bixinóides de forma individualizada. Já por espectrofotometria, são quantificados todos os pigmentos que absorvem na região do espectro considerada. Com isso, são quantificados outros carotenóides juntamente com a bixina e a norbixina e, normalmente, os teores de pigmentos encontrados por métodos espectrofotométricos apresentam-se ligeiramente superiores àqueles encontrados por CLAE. Entretanto, para análises de rotina de quantificação de pigmentos totais, o método espectrofotométrico é de rápida execução e apresenta menor custo.

De forma geral, verificou-se que nas condições empregadas no trabalho não ocorreu a saponificação da bixina em norbixina com o uso de solventes alcalinos. Condições essas verificadas em outros trabalhos citados na literatura, cujos teores de pigmento foram determinados por espectrofotometria (PIMENTEL, 1995). Sendo assim, deve-se estudar melhor a reação de saponificação dos pigmentos de urucum, avaliando isoladamente e em conjunto os fatores que a influenciam e a necessidade de emprego de metodologia adequada para esse fim.

\section{CONCLUSÃO}

Em termos da eficiência de extração, o melhor solvente extrator foi o $\mathrm{NH}_{4} \mathrm{OH}$ etanólico $2 \%$ que possibilitou o teor mais baixo de pigmentos residuais nas sementes.

As distintas metodologias empregadas na produção dos corantes de urucum deram origem a produtos com características diferenciadas.

A bixina foi o componente majoritário presente nos corantes, representando acima de $70 \%$ de todos os pigmentos extraídos.

Por cromatografia a líquido de alta eficiência não foi observado o desenvolvimento da reação de saponificação, nas condições de extração estudadas. Sendo assim, outros estudos são necessários para acompanhar o desenvolvimento da reação de saponificação dos pigmentos de urucum, bem como o emprego de técnicas adequadas para essa avaliação.

\section{ABSTRACT \\ EFFICIENCY OF SOLVENTS IN THE OBTENTION AND CHARACTERIZATION OF ANNATTO (Bixa orellana L.) PIGMENTS}

The present research aimed to verify the efficiency of different solvents in extraction of pigments from annatto seeds, as well as to product and to verify the characteristics of the obtained colorants. The solvents used were $\mathrm{KOH} 0.6 \%, \mathrm{NH}_{4} \mathrm{OH} 2 \%, \mathrm{NH}_{4} \mathrm{OH}$ ethanolic $2 \%$ and commercial ethanol. From data obtained with $\mathrm{KOH}$ $0.6 \%$ and $\mathrm{NH}_{4} \mathrm{OH} 2 \%$ it was possible to produce powdered colorants by spray-drying, and the hydroalcoholic and alcoholic extracts originated pasty colorants. The extraction efficiency was evaluated by residual content of bixin present in the seeds when the extractions were finished. The colorants were characterized through moisture content, total solids, ash, ammonia, potassium and by bixin and norbixin contents. The most efficient solvent was $\mathrm{NH}_{4} \mathrm{OH}$ ethanolic $2 \%$. The largest bixin content was found in the pasty colorant produced with ethanol $\left(27.7 \mathrm{~g} .100 \mathrm{~g}^{-1}\right)$, and in spite of what is described on literature, the concentrations of alkali that 
were used were not enough to convert bixin in norbixin and its salt. The different solvents interfered by increasing the concentration of compounds present in the produced colorants, such as ash, nitrogenated compounds and potassium. In all colorants produced the major pigment was bixin, even if the extracts were obtained by extraction using alkaline solution.

KEY-WORDS: BIXIN; NORBIXIN SALT; EXTRACTION METHODS.

\section{REFERÊNCIAS}

1 AGNER, A.R.; BARBISAN, L.F.; SCOLASTICI, C.; SALVADORI, D.M.F. Absence of carcinogenic and anticarcinogenic effects of annatto in the rat liver medium-term assay. Food Chemical Toxicology, v.42, p.1687-1693, 2004.

2 BARETH, A.; STROHMAR, W.; KITZELMANN, E. HPLC and spectrophotometric determination of annatto in cheese. European Food Research and Technology, v.215, p. 359-364, 2002.

3 COSTA, C.L.S.; CHAVES, M.H. Extração de pigmentos das sementes de Bixa orellana L.: uma alternativa para disciplinas experimentais de química orgânica. Química Nova, v.28, n.1, p.149152, 2005.

4 GOMES, J.C.; SILVA, M.H.L.; SILVA, C.O. Análise de alimentos. 2. ed. Viçosa: Editora UFV, 2003. $126 \mathrm{p}$.

5 LEVY, L.W.; RIVADENEIRA, D.M. Annatto. In: LAURO, G.J.; FRANCIS, F.J. (Eds.). Natural food colorants - science and technology. Chicago: Marcel Dekker, 2000. p.115-152.

6 LIMA, L.R.P.; OLIVEIRA, T.T.; NAGEM, T.J.; PINTO, A.S.; STRINGHETA, P.C.; TINOCO, A.L.A.; SILVA, J.F. Bixina, norbixina, quercetina e seus efeitos no metabolismo lipídico de coelhos. Brazilian Jounal of Veterinary Research and Animal Science, v.38, n.4, p.196-200, 2001.

7 MILLER, D.D. Food chemistry: a laboratory manual. In: NIELSEN, S.S. (Ed.) Food analysis. New York: Klumer Academic, 1999. p. 18-24.

8 INSTITUTO ADOLFO LUTZ. Normas analíticas do Instituto Adolfo Lutz: métodos químicos e físicos para análise de alimentos. 3. ed. São Paulo: Nobel, 1985. 375 p.

9 PIMENTEL, F.A. Avaliação de métodos de obtenção e de estabilidade de pigmentos de sementes de urucum. Viçosa, 1995. 132 p. Dissertação (Mestrado em Ciência e Tecnologia de Alimentos) Universidade Federal de Viçosa.

10 PIMENTEL, F.A.; STRINGHETA, P.C. Produção de corantes de urucum em pó, por meio de precipitação ácida, a partir de extratos obtidos em diferentes soluções extratoras. Revista Brasileira de Corantes Naturais, v.3, p.53-57, 1999.

11 PRENTICE-HERNANDEZ, C.; RUSIG, O.; CARVALHO, P.R.N. Efeito do pH na quantidade de bixina obtida em extratos alcalinos de urucum (Bixa orellana L.). Revista Brasileira de Corantes Naturais, v.1, n.1, p.182-187, 1992.

12 PRENTICE-HERNANDEZ, C.; RUSIG, O. Extrato de urucum (Bixa orellana L.) obtido utilizando álcool etílico como solvente. Arquivos de Biologia e Tecnologia, v.35, n.1, p.63-74, 1992.

13 PÓVOA, M.E.B. Extração do corante de urucum (Bixa orellana L.) com diversos solventes. Revista Brasileira de Corantes Naturais, v.1, n.1, p.153-157, 1992.

14 SAS Institute Inc. SAS Statistical Software. Version 9.1. Cary, NC, 2002.

15 SILVA, P. I. Métodos de extração e caracterização de bixina e norbixina em sementes de urucum (Bixa orellana L.). Viçosa, 2007. 145 p. Dissertação (Mestrado em Ciência e Tecnologia de Alimentos) - Universidade Federal de Viçosa.

16 SOUZA, E.C. Estudo químico e físico-químico dos pigmentos do urucum (Bixa orellana) utilizando metodologia simplificada. Lavras, 2000. 45 p. Dissertação (Mestrado em Ciência de Alimentos) Universidade Federal de Lavras. 
17 STRINGHETA, P.C.; MASCARENHAS, J.M.O.; PONTES, L.V.; SILVA, J.N.; REIS, F.P. Determinação do teor de bixina em sementes de urucum. Revista Brasileira de Corantes Naturais, v.3, p. 47-52, 1999.

18 TOCCHINI, L.; MERCADANTE, A.Z. Extração e determinação, por CLAE, de bixina e norbixina em coloríficos. Ciência e Tecnologia de Alimentos, v.21, n.3, p. 310-313, 2001. 